\title{
Lung cancer stem cells
}

\author{
Sharon R. Pine ${ }^{\mathrm{a}}$, Blair Marshall ${ }^{\mathrm{b}}$ and Lyuba Varticovski ${ }^{\mathrm{a}, *}$ \\ ${ }^{a}$ Center for Cancer Research, NCI, NIH, Bethesda, MD, USA \\ ${ }^{\mathrm{b}}$ Georgetown University, Washington, DC, USA
}

\begin{abstract}
Lung cancer remains a major cause of cancer-related lethality because of high incidence and recurrence in spite of significant advances in staging and therapies. Recent data indicates that stem cells situated throughout the airways may initiate cancer formation. These putative stem cells maintain protumorigenic characteristics including high proliferative capacity, multipotent differentiation, drug resistance and long lifespan relative to other cells. Stem cell signaling and differentiation pathways are maintained within distinct cancer types, and destabilization of this machinery may participate in maintenance of cancer stem cells. Characterization of lung cancer stem cells is an area of active research and is critical for developing novel therapies. This review summarizes the current knowledge on stem cell signaling pathways and cell markers used to identify the lung cancer stem cells.
\end{abstract}

Keywords: $\mathrm{ABC}$ transporters, drug resistance, hedgehog, notch, non-small cell lung cancer, side population, small cell lung cancer, stem cells, Wnt

\section{Introduction}

Lung cancer is one of the most frequently occurring malignancies accounting for $18 \%$ of cancers in men world wide and $21 \%$ in Western countries [70]. Approximately 213,380 new cases of lung cancer are projected to be diagnosed in 2007 and at least 160,000 deaths are expected to occur next year from this disease in the United States. Annual deaths from lung cancer exceed deaths due to breast, colon, and prostate cancers combined [45]. Despite numerous therapeutic advances during the last thirty years, the majority of patients present with advanced disease because early stage lung cancer is asymptomatic and there are no standard screening procedures in place for high risk populations. Even with the most up-to-date imaging, staging, and surgical modalities, the five-year survival rate following adjuvant therapy for patients with stage IB to IIIA ranges only from 5-15\% [48,101]. In addition, patients with small cell lung cancer (SCLC) frequently present with metastases regardless of the primary tu-

* Corresponding author: Lyuba Varticovski, MD, Center for Cancer Research, LHC, Building 37, Room 3060, National Cancer Institute, Bethesda, MD 20892, USA. E-mail: varticol@mail.nih.gov. mor size [74]. These data support the notion that early disseminated disease in patients with lung cancer is due to enrichment of cancer stem cells in these tumors.

Commonly thought of as a single disease, lung cancer actually represents a group of neoplasias arising from phenotypically diverse cells $[9,98]$. These encompass several distinct tumor types: squamous cell carcinoma (SCC), adenocarcinoma/bronchoalveolar (nonsmall cell lung cancer, NSCLC), and neuroendocrine carcinomas. Despite the histological and biologic differences, squamous cell and NSCLC are treated as a homogeneous group and patients presenting with these lesions are treated similarly. The neuroendocrine carcinomas include small cell (SCLC), large cell, atypical and typical carcinoids. Although these tumors have common neuroedocrine origin, they are histologically diverse with widely varying survival rates from less than $5 \%$ for SCLC to greater than $90 \%$ for well differentiated, slow growing carcinoid tumors $[59,74]$.

Ninety percent of lung cancer is caused, at least in part, by cigarette smoking [64]. Despite increased awareness of the carcinogenic potential of cigarette smoke, the incidence of lung cancer continues to increase in parallel with an increase in predominantly young smokers. There has been a shift in lung cancer 
pathology over the past few decades due to changes in cigarette design and subsequent changes in inhalation patterns [102]. In the 1950 's, less than $1 \%$ of all cigarettes contained filters and by the late 1990's, more than $95 \%$ contained filters. Prior to this change, squamous cell was the predominant cell type. Squamous cells populate the proximal and central airways. With deeper inhalation techniques associated with the use of filtered cigarettes, peripheral adenocarcinoma has taken over as the most common non-small lung cancer subtype.

Despite the fact that the majority of lung cancers can be attributed to smoking, $10 \%$ arise in never-smokers, suggesting that several genetic and environmental factors participate in lung carcinogenesis, including genetic polymorphisms, and exposure to radon, cooking fumes, asbestos, heavy metals, and passive smoking. A disproportionate number of never-smoking lung cancer patients are women, and the incidence of lung cancer in never-smoking Asian women in particular is increasing [30]. A high indoor concentration of benzo pyrenes due to indoor coal burning, other environmental causes, and possibly human papilloma virus (HPV) have been linked to this trend [54].

The prime role of the airways (trachea, bronchi, bronchioles and terminal bronchioles) is to conduct air into and out of the lung and to form a first line of defense against undesired constituents of inhaled air. The airways are continuously exposed to pathogens, irritants, pollutants and agents that produce oxidative stress; therefore, the composition of the respiratory tract surface is very important. The upper airways contain specialized cell types such as ciliated cells and mucous secreting goblet cells. The lower conducting airways (respiratory bronchioles, alveolar ducts and alveolar sacs) participate in gas exchange by diffusion. The alveolar epithelial surface comprises essentially two cell types, the alveolar epithelial type I cell and the cuboidal alveolar epithelial type II cell. Type I cells flatten out and in this way constitute approximately $95 \%$ of the total alveolar surface, whereas type II cells are more numerous and produce surfactant [64].

In the last several years, there is growing evidence that solid tumors are composed of cells with different biological properties, and the capability to sustain tumor growth resides in a small fraction of tumor cells, termed cancer stem cells or tumor-initiating cells $[18,69,78]$. Tumor-initiating cells have been identified in many types of cancers by sorting cell subpopulations based on surface marker expression patterns, and transplantation into animal models. These stud- ies have shown that tumor-initiating cells are responsible for tumor formation and progression, and have stem/progenitor cell properties such as self-renewal, long-term proliferation and expression of genes associated with stem cells of the organ $[87,100]$. The purpose of this review is to provide recent information about identification and characterization of cancer stem cells within the lung.

\section{Pathways in stem cell development and cancer stem cells}

\subsection{Common pathways}

Much understanding of cancer stem cell biology comes from earlier studies of normal and malignant hematopoiesis. Recent information on normal embryonic and neuronal stem cells, as well as breast and brain cancer stem cells describes common features that define normal and malignant stem cells. This information may be applicable to cancer stem cells from many other organs, including the lung. Cancer stem cells derived either from normal stem cells or from differentiated cells that reverted to a stem cell-like phenotype result in deregulation of the fundamental characteristic of stem cell: the capacity for asymmetric division and self-renewal. The Notch, Hedgehog and Wnt pathways define normal stem cells and guide the behavior of normal pulmonary precursors within several different lineages. Lung cancer of specific phenotypes or locations within the lung that arise from inappropriate expansion of pulmonary cancer stem cell lineages may be caused by abnormal signaling in these pathways. Here, we examine the Notch, Hedgehog and Wnt pathways in lung development and integrate them with current knowledge about lung cancer stem cells. Details of the signaling pathways can be found in [67].

\subsection{Notch pathway}

Notch signaling requires asymmetry between neighboring cells and is initiated by activation of Notch receptors by ligands present on adjoining cells. Proteolytic cleavage steps generate a Notch intracellular domain fragment (Notch ICD) that associates with the latent transcriptional activator $\mathrm{CBF}-1$ (also referred to as RBP-Jk and SuH), rendering it active. The Notch pathway participates in development and maintenance of normal tissues, by regulation of differentiation and cell cycle progression. Notch pathway is present in 
the developing lung and lung cancer cells at the receptor (Notch1-Notch4), ligand (Jagged1,2 and Deltalike, Dll1,3,4), and downstream effector (Hes1, Hey1 and HeyL) levels. In the mouse, Notch1 is expressed in the distal lung endoderm as early as E11.5 [44,76]. Notch 2 and Notch 3 are expressed in the developing lung mesenchyme that surrounds the primitive epithelium, Notch3 is expressed in epithelial cells $[44,76]$ and Notch4 in endothelial cells [76]. Notch 1 and 3 are also expressed in Clara cells of adult lung. The Notch ligand, Jagged 1, is expressed in lung mesenchyme and lung vessels, and Jagged 2 is in the peripheral lung mesenchyme [76] suggesting that Jagged2 interacts with Notch1-expressing airway epithelial cells in the developing lung. Expression of Dll1 is restricted to pulmonary neuroendocrine cells $[10,44,76]$ and may interact with Notch1 and 3 expressed on airway epithelial Clara cell progenitors.

Among Notch effectors, Hes1 is expressed in fetal mouse lung and is co-expressed with Notch 1 and 3 in Clara cells [44]. Pulmonary expression of other Notch pathway effectors in the lung is not known, although Hey 1 and Hey 2 are expressed in the adult lung [90] and HeyL is expressed in lung vasculature [57]. The Notch pathway effectors act as transcriptional repressors to inhibit tissue-specific differentiation proteins, such as mASH1 in mice [36]. mASH1 expression is confined to neuroepithelial bodies and pulmonary neuroepithelial cells, and mice lacking maSH1 in the lungs have no neuroendocrine cells [13]. This suggests that neuroendocrine cell differentiation is regulated by Notch1. Further information on the role of Notch in lung development can be found elsewhere [17].

There are several reasons to suggest that Notch participates in maintaining lung cancer stem cells. Notch1 and 3 and the downstream Notch effector, Hes-1, are expressed in NSCLC cell lines, although they are rarely detected in SCLC cell lines [14,17,19]. SAGE expression profiling data collected in a range of cancer cell lines also implicates the Notch effectors Hes1, Hey1 and HeyL in NSCLC (Gene expression Omnibus Dataset 217, Cancer Genome Anatomy Project SAGE library collection, (http://www.ncbi.nlm.nih.gov/geo). hASH1 expression is inhibited by Notch signaling and hASH1 is elevated in neuroendocrine SCLC, but is rarely expressed in NSCLC [4]. Thus, hASH1 expression in the lung neuroendocrine cells may be regulated by Notch signaling. Deregulated Notch signaling may play a role in SCLC pathogenesis. SCLC cells are growth-inhibited by overexpression of activated Notch1 and $2[88,89]$. Because Notch signaling is a key pathway in Clara and neuroendocrine cell development and is dysregulated in NSCLC and SCLC, Notch pathway may be an important therapeutic target in lung cancer.

\subsection{Hedgehog pathway}

Hedgehog $(\mathrm{Hh})$ is a morphogen that acts in a shortor long-range fashion on various tissue types [26]. In mammals, there are three $\mathrm{Hh}$ proteins: Sonic Hh, Indian Hh, and Desert Hh. During lung embryogenesis $\mathrm{SHh}$, expressed in the budding airway epithelium, is required for lung development and is a key mediator of epithelial-mesenchymal interactions [7]. SHh-null mouse embryos fail to separate trachea from esophagus, resulting in formation of a rudimentary lung sac from a single tracheo-esophageal tube due to failure of branching and growth after formation of primary lung buds [60]. Over-expression of SHh from the SP-C promoter in transgenic mice results in increased epithelial and mesenchymal proliferation [7]. Patched (PTCH) is a surface membrane receptor that is required for $\mathrm{SHh}$ signaling that is highly expressed in mesenchyme surrounding the terminal lung buds, and knock-down of PTCH in mice also results in decreased lung branching morphogenesis. Upon $\mathrm{SHh}$ binding, $\mathrm{PTCH}$ receptors release the smoothened (SMO) protein resulting in activation of GLI, which functions as transcriptional regulator. Knockdown of SMO, GLI2 and GLI3 in mice results in absence of lung development [98].

Dysregulation of the Hh pathway has been welldocumented in SCLC. The Hh pathway can be constitutively activated by mutations in SMO and amplification of GLI in several cancer types [2]. GLI expression in normal cells is restricted to precursor cells, and may, therefore, participate in cancer stem cell selfrenewal. Persistent SHh pathway activation in SCLC, driven by a high expression of SHh, PTCH and GLI1, is observed in primary SCLC, but rarely in NSCLC cell lines [95]. The Hh pathway can be inhibited by cyclopamine, a naturally-occurring compound which specifically targets SMO [99]. Treatment of SCLC cell lines and cell line xenografts with cyclopamine leads to tumor growth arrest, and SCLC cell lines that overexpress GLI1 can be protected from inhibition by cyclopamine [99]. Thus, vulnerability of SCLC to a blockade of SHh signaling may provide a new therapeutic target approach. 


\subsection{Wht pathway}

Wnt signaling is a critical component of early lung organogenesis and disease [75,97]. Several of 19 known Wnts are expressed in the adult lung: Wnt2, Wnt5a, and Wnt 11 are expressed in the mesenchyme, and $\mathrm{Wnt} 5 \mathrm{a}$ and $\mathrm{Wnt} 7 \mathrm{~b}$ are expressed in the pulmonary epithelium [53,58,86,96]. Studies of knockout mice reveal the importance of Wnts in lung development [39]. The canonical Wnt pathway involves binding to one of 10 known Frizzled (Fzd) receptors leading to nuclear translocation of $\beta$-catenin [51] and transcriptional activaton. Expression of the Wnt inhibitor Dickkopf-1 (Dkk-1) has been observed in the distal epithelium, and Dkk1 inhibits branching morphogenesis [20].

Disruption of the Wnt pathway has been implicated in non-small cell lung cancer. Wnt 2 is overexpressed in NSCLC, and inhibition of Wnt2-mediated signaling by siRNA or a monoclonal antibody results in apoptosis of NSCLC cell lines [105]. Wnt inhibitory factor (WIF1), a secreted Wnt antagonist, inhibits NSCLC cell line growth in vitro and in vivo, and is also downregulated in NSCLC [50]. WIF1 silencing is associated with hypermethylation of its promoter. Methylation-silencing of WIF1 is a common mechanism for aberrant activation of Wnt signaling in lung cancer [39]. Disheveled (dvl) proteins are positive mediators of Wnt signaling. Dvl 3 is overexpressed in $75 \%$ of freshly microdissected NSCLC tissue specimens [92]. Inhibition of dvl1, 2 and 3 resulted in decreased $\beta$-catenin, TCF-mediated transcription and inhibition of cell growth in NSCLC cell lines [92]. One can speculate that blocking the Wnt signaling pathway may be also an attractive target for therapeutic agents.

\section{Stem cell gene expression}

In addition to genes involved in the Notch, Wnt and $\mathrm{HH}$ pathways, other genetic markers are associated with cancer stem cells. One of the most interesting genes, Oct-4 (also known as OCT3 or POU5F1), is a mammalian POU family transcription factor required for maintenance of embryonic stem (ES) cell pluripotentcy [73]. Oct-4 expression is downregulated in all differentiated somatic cell types in vitro as well as in vivo by increased DNA methylation and structural changes involving immediate upstream regulatory region $[8,93]$.

Oct- 4 may be regulated by the Wnt pathway and has the ability to reprogram committed somatic cells, inducing their dedifferentiation by reverting them to a more developmentally potent state [33]. Keratinocytes that overexpress Oct-4 can differentiate into other cell types, based on expression of genes characteristic of neuronal cells: nestin, neuN, and Sox-1. This indicates that Oct-4 may be a master regulator of the pluripotent state in mammalian cells.

Recently, miRNAs have been implicated in the control of self-renewal in stem cells [38]. In particular, studies in Drosophila and mice suggest that miRNAs are important regulators of stem cell differentiation, self-renewal and division [38]. Georgantas et al. recently found 33 miRNAs expressed in $\mathrm{CD}_{34}{ }^{+}$hematopoietic stem-progenitor cells that were important for haematopoietic differentiation [31] and miRNA-221, -222 and -223 have been implicated in the inhibition of granulopoiesis and erythropoiesis while miRNA-155 plays a role in normal human myelopoiesis, lung differentiation, and erythropoieis [31]. Also, recent work from NCI has shown that high hsa-mir-155 and low hsa-let-7a-2 expression have been associated with poor outcome in lung cancer [104].

\section{Stem cells and drug resistance}

Another important characteristic of cancer and normal stem cells is resistance to toxic compounds [78]. This concept is specifically applicable to airborne pollutants in reference to lung cancer. Bronchiolar progenitor cells localized within neuroepithelial body (NEB) express reduced levels of cytochrome p450 xenobiotic metabolizing enzymes [79] which reduces intracellular levels of lipophilic toxic metabolites allowing airways stem cells to survive frequent airborne injuries. These same cells also exhibit efficient drug efflux or a 'side population' (SP) phenotype as detected by efflux of Hoechst and other dyes due to ATP Binding Cassette (ABC) transporters [91]. Many ABC transporters, such as ABCB1 (P-glycoprotein, MDR1), ABCC1 (multidrug resistance-associated protein 1, MRP1), ABCG2 (breast cancer resistance protein, BCRP,) and others are highly expressed in lung bronchial epithelium and alveolar type II cells $[93,106]$. Over-expression of MDR-1 is detected in lung tumors prior to therapy [82] and enhanced efflux of doxorubicin, cisplatinum, and mitoxantrone is associated with resistance to chemotherapy.

It is not known whether SP cells isolated from lung truly exhibit bona-fide lung stem cell function [63, 91] but SP-associated drug efflux and resistance to 
chemotherapies occur in lung and other tissue tumor cell lines in vitro. SP cells have stem cell characteristics including enhanced clonogenicity [80] and tumor formation in vivo $[11,41,52,65]$ (Pine and Varticovsky, unpublished).

Recently, a side population (SP) has been identified in the lungs of PTEN deficient mice [103] and a variety of lung cancer cell lines [42]. The latter are tumorigenic in vivo, display increased invasive capability and have increased expression of ABC transporters. In addition, Eramo et al. [25] showed that, similar to colon and brain cancer, lung cancer $\mathrm{CD} 133^{+}$cells are resistant to conventional chemotherapy, including cisplatin, etoposide, gemcitabine, vinorelbine, docetaxel, doxorubicin, and daunorubicin.

Aldehyde Dehydrogenase (ALDH), a drug-resistance gene found in normal hematopoietic stem cells [46], was recently found in several types of cancer initiating cells, including NSCLC [71,83]. Expression of ALDH is regulated by the Hh pathway [27] and blockade of hedgehog signaling inhibits pancreatic cancer invasion and metastases [28]. ALDH1 participates in the oxidation of retinal to all-trans retinoic acid [81], and confers drug resistance to chemotherapeutic agents, such as cyclophosphamide, by an uncertain mechanism [5].

\section{Evidence of cancer stem cells in lung cancer mouse models}

In the mouse, stem cell niches have been identified in the lung that may be targets for cancer initiation and promotion. These stem cell niches maintain epithelial differentiation in the airways $[32,43]$. Of particular interest is a sub-type of Clara cells residing at the brochioalveolar junction that is able to regenerate Clara and alveolar cells lining the terminal bronchioles and alveoli [32]. A recent study [49] provided exciting insights about how these bronchioalveolar stem cells may be involved in normal lung-tissue homeostasis and development of lung cancer. The bronchioalveolar stem cells co-express Clara, alveolar cell markers, and stem cell markers, Sca-1 and CD34, and are refractory to the lung-damaging agent, naphthalene. These cells are likely candidates for NSCLC stem cells because of their capacity for self-renewal and tissue regeneration. Expression of oncogenic K-ras in mouse broncheoalveolar stem cells resulted in heightened proliferation as compared to differentiated alveolar cells. These features are similar to expansion of broncheoalveolar stem cells in adenocarcinoma [49]. Validation of these cells as tumor-repopulating cells and identification of human broncheoalveolar stem cells have not been reported.

\section{Methods used for identification and characterization of cancer stem cells}

\subsection{Cell surface markers}

Although we tend to think of a tumor as a single type of tissue, even undifferentiated hematopoietic tumors contain cells that differ by surface markers that mark the capacity for self-renewal and differentiation. Theories proposing that cancers contain stem cells were published over 20 years ago [62], but only ten years ago experimental evidence was provided that tumor-initiating cells in human acute myeloid leukaemia (AML) share cell surface (CD34+CD38-) phenotype with normal hematopoietic stem cells [12]. Identification of hematopoietic cells with long-term and short-term proliferative capacity has provided information on stem cells and lineage-specific progenitor cells. Several cell surface markers indicate the potential stem cell characteristics of epithelial tumors. Table 1 lists known or potential stem cell markers in lung cancer.

CD44 is a ubiquitously expressed multispanning transmembrane cell-surface adhesion glycoporotein that mediates cell-matrix and cell-cell interactions. Expression of CD44 correlates with drug resistance and poor prognosis in many malignancies [61]. In addition to hyaluronic acid, CD44 can be bound by fibrinogen, fibronectin, collagen, laminin, FGF-2, and other heparin-binding growth factors $[61,66]$. CD44 also binds to, and is upregulated by ostopeontin, an inflammatory cytokine associated with metastatic progression, and this interaction may constitute a feedback loop for survival of disseminated cells closely resembling the origin of cancer stem cells [22]. CD44 is found in hematopoietic, breast, and other malignant stem cells, including SCLC and NSCLC [55]. Alternative splicing of this complex proteoglican was correlated with survival in patients with NSCLC [56].

CD133 (prominin-1) is a glycoprotein with five membrane-spanning domains [85] that was initially detected in endothelial cells, but recently found alone or in combination with other cell surface markers in brain [94], colon and pancreatic cancer-initiating stem cells. CD133 expression correlates with drug resistance [68] and brain tumor-derived and cell lines-sorted CD133 positive cells have a distinct gene expression profile [6]. A recent paper identified CD133 as a lung CSC marker. Using CD133+ ${ }^{+}$cells isolated from human lung tumors of diverse histological type, the authors reported that these cells grew indefinitely as tumor spheres, although a large number of cells, i.e., $10^{4}$, 
Table 1

Cellular markers that may contribute to lung cancer stem cell properties

\begin{tabular}{|c|c|c|c|c|c|}
\hline \multirow[t]{2}{*}{ Marker } & \multirow[t]{2}{*}{ Name } & \multirow[t]{2}{*}{ Cellular function } & \multirow[t]{2}{*}{ Ligand } & \multicolumn{2}{|c|}{ Cancer Stem Cell Marker } \\
\hline & & & & Lung & Other \\
\hline CD44 & Pgp-1 & hyaluronic acid receptor & $\begin{array}{l}\text { hyaluronic acid and } \\
\text { hyaluronate-interacting } \\
\text { growth factors, osteopontin }\end{array}$ & NSCLC & hematopoietic, breast \\
\hline CD133 & Prominin-1 & unknown & unknown & unknown & brain, colon, pancreas \\
\hline CD117 & $\begin{array}{l}\text { stem cell factor receptor, } \\
\text { SCFR }\end{array}$ & growth factor receptor & stem cell factor, SCF & unknown & hematopoietic \\
\hline CD87 & $\begin{array}{l}\text { urokinase plasminogen } \\
\text { activator }\end{array}$ & uPA receptor & uPA & NSCLC & unknown \\
\hline PTCH & Patched & $\begin{array}{l}\text { differentiation, branching } \\
\text { morphogenesis }\end{array}$ & sHH, iHH, dHH & unknown & unknown \\
\hline Notch & Notch & $\begin{array}{l}\text { differentiation, cell cycle } \\
\text { progression }\end{array}$ & $\begin{array}{l}\text { Jagged-1, Jagged-2, DLL1, } \\
\text { DLL3, DLL4 }\end{array}$ & unknown & unknown \\
\hline Fzd & Frizzled & $\begin{array}{l}\text { development, branching } \\
\text { morphogenesis }\end{array}$ & Wnt family members & unknown & unknown \\
\hline SP & side population & drug resistance & & SC/NSCLC & $\begin{array}{l}\text { hematopoietic, brain, } \\
\text { breast }\end{array}$ \\
\hline ALDH & $\begin{array}{l}\text { aldehyde } \\
\text { dehydrogenase }\end{array}$ & $\begin{array}{l}\text { alcohol metabolism, } \\
\text { unknown }\end{array}$ & acetaldehyde & unknown & $\begin{array}{l}\text { hematopoietic, breast, } \\
\text { prostate }\end{array}$ \\
\hline
\end{tabular}

were required for tumor reconstitution in mice [25]. Thus, these data support our investigation into the characterization, modulation and targeting of lung CSC.

Expression of CD117 (c-Kit) and its ligand, stem cell factor in neuroendocrine tumors of the lung and other organs has been known since the early 1990's [40]. Although less than a third of patients with adenocarcinomas and squamous tumors express CD117, its expression is associated with poorer prognosis in early stage patients [72]. In contrast to GI stromal tumors (GIST), no mutations of CD117 are found in these tumors, and Phase II clinical trials failed to demonstrate clinical efficacy of Abl/c-Kit/PDGF inhibitor, imatinib, in lung cancer patients $[3,23]$ or in patients with other neuroendocrine tumors [34] selected for expression of c-Kit. Thus, it is unlikely that CD117 marks an early progenitor in these tumors. Additional trials using combination of imatinib with conventional chemotherapies are ongoing.

Expression of other tyrosine kinase (TK) receptors, notably epidermal growth factor receptor (EGFR), c-Met and platelet-derived growth factor receptor (PDGF), are associated with poor prognosis in patients with NSCLC. In addition, Asian women with adenocarcinoma of the lung show a significantly higher response rate to gefitinib, an EGFR tyrosine kindase inhibitor. Several EGFR kinase domain mutations may confer susceptibility to EGFRinhibitors [16] whereas T790M mutation has emerged as a marker of resistance to these molecular targeted therapies [84]. In addition, signaling by EGFR requires ERBB3/PI 3-K/Akt and this pathway can be activated by overexpression of MET oncogene in EGFR inhibitor-resistant cells [24].
Other cell surface markers, such as several chemokines and urokinase plasminogen activator (uPA) and its receptor, uPAR (CD87), have been found in SCLC, co-express CD44 and the MDR1 drug resistance gene [35]. The role of these proteins in contributing to lung cancer is not known.

\subsection{In vitro expansion and in vivo validation of lung cancer stem cells}

Validation of cancer stem cells based on expression of cell surface markers is hampered by inherent difficulties in ex-vivo expansion of the putative stem cell population and visualization of cancer cells in the lung. By definition, the capacity of self renewal parallels reconstitution of the original population of cells. Thus, growth of cells in vitro or in vivo, initially sorted based on a specific stem cell marker, results in reconstitution of the original phenotype and loss of stem cell enrichment. Several investigators reported that plating individual cells in semisolid media, such as collagen or Matrigel, in presence of epidermal growth factor and basic FGF generates 3-dimensional spheroid structures that preserve stem cell markers [15]. Although mathematical models have provided a useful guide to estimate cell number in these structures [21], further characterization of these cells requires dissociation into single cell suspension. Selection of cells that survive sublethal doses of chemotherapeutic agents in vitro has been proposed for selection of cancer stem cells, but this will primarily identify drug resistant cells. Further studies on methods that allow expansion of cancer stem 
cells in vitro are critical for their characterization and development of stem cell-targeted therapies.

Validation that cancer stem cells form tumors in vivo requires implantation into immunosuppressed mice. Orthotopic implantation of lung cancer into the mouse has been shown to be superior to commonly used subcutaneous (Orthopic) methods for tumor growth and drug response. Intrabronchial and percutaneous implantation into lung parenchyma has been used with variable success [47]. In addition, visualization of tumor growth is best when cells are labeled with fluorescent or bioluminescent markers. In vivo generation of lung cancer from isolated cancer stem cells using a combination of these methods provides a valuable preclinical model for testing novel cancer stem-cell targeted therapies.

\section{Conclusions}

Although molecular analysis of gene expression [1, $29,37]$ has contributed greatly over the past 10 years to understanding molecular mechanisms in development of lung cancer, we have not impacted disease survival, altered treatment strategies, or refined staging system. Recent microarray data, the lung metagene model, may permit more accurate staging for these cancers and define those which will benefit from which adjuvant therapy [77]. Combination of these techniques with development of specific agents that target cancer stem cells will provide much needed information for improving the outcome of patients with lung cancer.

\section{Acknowledgments}

The authors thank Curtis C. Harris for review of the manuscript and support of this work, and Karen MacPherson for bibliographical assistance.

\section{References}

[1] S.A. Ahrendt, S.C. Yang, L. Wu, C.M. Roig, P. Russell, W.H. Westra, J. Jen, M.V. Brock, R.F. Heitmiller and D. Sidransky, Molecular assessment of lymph nodes in patients with resected stage I non-small cell lung cancer: preliminary results of a prospective study, J Thorac Cardiovasc Surg 123 (2002), 466-473.

[2] A. Altaba, P. Sanchez and N. Dahmane, Gli and hedgehog in cancer: tumours, embryos and stem cells, Nat Rev Cancer 2 (2002), 361-372.

[3] O. Altundag, K. Altundag, C. Boruban, Y.S. Silay and S. Turen, Imatinib mesylate lacks activity in small cell lung carcinoma expressing c-kit protein: a Phase II clinical trial, Cancer 104 (2005), 2033-2034.
[4] D.W. Ball, C.G. Azzoli, S.B. Baylin, D. Chi, S. Dou, H. Donis-Keller, A. Cumaraswamy, M. Borges and B.D. Nelkin, Identification of a human achaete-scute homolog highly expressed in neuroendocrine tumors, Proc Natl Acad Sci USA 90 (1993), 5648-5652.

[5] C. Baum, L.J. Fairbairn, M. Hildinger, L.S. Lashford, S. Hegewisch-Becker and J.A. Rafferty, New perspectives for cancer chemotherapy by genetic protection of haematopoietic cells, Expert Rev Mol Med 1999 (1999), 1-28.

[6] D. Beier, P. Hau, M. Proescholdt, A. Lohmeier, J. Wischhusen, P.J. Oefner, L. Aigner, A. Brawanski, U. Bogdahn and C.P. Beier, CD133(+) and CD133(-) glioblastomaderived cancer stem cells show differential growth characteristics and molecular profiles, Cancer Res 67(9) (1 May 2007), 4040-4015.

[7] S. Bellusci, J. Grindley, H. Emoto, N. Itoh and B.L. Hogan, Fibroblast growth factor 10 (FGF10) and branching morphogenesis in the embryonic mouse lung, Development 124 (1997), 4867-4878.

[8] E. Ben Shushan, H. Sharir, E. Pikarsky and Y. Bergman, A dynamic balance between ARP-1/COUP-TFII, EAR-3/COUPTFI, and retinoic acid receptor:retinoid $\mathrm{X}$ receptor heterodimers regulates Oct-3/4 expression in embryonal carcinoma cells, Mol Cell Biol 15 (1995), 1034-1048.

[9] A. Berns, Stem cells for lung cancer? Cell 121 (2005), 811813.

[10] B. Bettenhausen, d.A. Hrabe, D. Simon, J.L. Guenet and A. Gossler, Transient and restricted expression during mouse embryogenesis of Dll1, a murine gene closely related to Drosophila Delta, Development 121 (1995), 2407-2418.

[11] R.I. Bhatt, M.D. Brown, C.A. Hart, P. Gilmore, V.A. Ramani, N.J. George and N.W. Clarke, Novel method for the isolation and characterisation of the putative prostatic stem cell, Cytometry A 54 (2003), 89-99.

[12] D. Bonnet and J.E. Dick, Human acute myeloid leukemia is organized as a hierarchy that originates from a primitive hematopoietic cell, Nat Med 3 (1997), 730-737.

[13] M. Borges, R.I. Linnoila, H.J. van de Velde, H. Chen, B.D. Nelkin, M. Mabry, S.B. Baylin and D.W. Ball, An achaetescute homologue essential for neuroendocrine differentiation in the lung, Nature 386 (1997), 852-855.

[14] H. Chen, A. Thiagalingam, H. Chopra, M.W. Borges, J.N. Feder, B.D. Nelkin, S.B. Baylin and D.W. Ball, Conservation of the Drosophila lateral inhibition pathway in human lung cancer: a hairy-related protein (HES-1) directly represses achaete-scute homolog-1 expression, Proc Natl Acad Sci USA 94 (1997), 5355-5360.

[15] R.B. Clarke, Isolation and characterization of human mammary stem cells, Cell Prolif 38 (2005), 375-386.

[16] C.D. Coldren, B.A. Helfrich, S.E. Witta, M. Sugita, R. Lapadat, C. Zeng, A. Baron, W.A. Franklin, F.R. Hirsch, M.W. Geraci and P.A. Bunn, Jr., Baseline gene expression predicts sensitivity to gefitinib in non-small cell lung cancer cell lines, Mol Cancer Res 4 (2006), 521-528.

[17] B.J. Collins, W. Kleeberger and D.W. Ball, Notch in lung development and lung cancer, Semin Cancer Biol 14 (2004), 357-364.

[18] J.D. Crapo, B.E. Barry, P. Gehr, M. Bachofen and E.R. Weibel, Cell number and cell characteristics of the normal human lung, Am Rev Respir Dis 126 (1982), 332-337.

[19] T.P. Dang, A.F. Gazdar, A.K. Virmani, T. Sepetavec, K.R. Hande, J.D. Minna, J.R. Roberts and D.P. Carbone, Chromosome 19 translocation, overexpression of Notch3, and human lung cancer, J Natl Cancer Inst 92 (2000), 1355-1357. 
[20] S.P. De Langhe, F.G. Sala, P.M. Del Moral, T.J. Fairbanks, K.M. Yamada, D. Warburton, R.C. Burns and S. Bellusci, Dickkopf-1 (DKK1) reveals that fibronectin is a major target of Wnt signaling in branching morphogenesis of the mouse embryonic lung, Dev Biol 277 (2005), 316-331.

[21] P.P. Delsanto, M. Griffa, C.A. Condat, S. Delsanto and L. Morra, Bridging the Gap between mesoscopic and macroscopic models: the case of multicellular tumor spheroids, Phys Rev Lett 94 (2005), 148105.

[22] B. Desai, M.J. Rogers and M.A. Chellaiah, Mechanisms of osteopontin and CD44 as metastatic principles in prostate cancer cells, Mol Cancer 6 (2007), 18.

[23] G.K. Dy, A.A. Miller, S.J. Mandrekar, M.C. Aubry, R.M. Langdon, Jr., R.F. Morton, S.E. Schild, J.R. Jett and A.A. Adjei, A phase II trial of imatinib (ST1571) in patients with c-kit expressing relapsed small-cell lung cancer: a CALGB and NCCTG study, Ann Oncol 16 (2005), 1811-1816.

[24] J.A. Engelman, K. Zejnullahu, T. Mitsudomi, Y. Song, C. Hyland, J.O. Park, N. Lindeman, C.M. Gale, X. Zhao, J. Christensen, T. Kosaka, A.J. Holmes, A.M. Rogers, F. Cappuzzo, T. Mok, C. Lee, B.E. Johnson, L.C. Cantley and P.A. Janne, MET Amplification Leads to Gefitinib Resistance in Lung Cancer by Activating ERBB3 Signaling, Science (2007).

[25] A. Eramo, F. Lotti, G. Sette, E. Pilozzi, M. Biffoni, A. Di Virgilio, C. Conticello, L. Ruco, C. Peschle and R. De Maria, Identification and expansion of the tumorigenic lung cancer stem cell population, Cell Death Differ 15 (2008), 504-514.

[26] M. Evangelista, H. Tian and F.J. De Sauvage, The hedgehog signaling pathway in cancer, Clin Cancer Res 12 (2006), 5924-5928.

[27] G. Feldmann, S. Dhara, V. Fendrich, D. Bedja, R. Beaty, M. Mullendore, C. Karikari, H. Alvarez, C. Iacobuzio-Donahue, A. Jimeno, K.L. Gabrielson, W. Matsui and A. Maitra, Blockade of hedgehog signaling inhibits pancreatic cancer invasion and metastases: a new paradigm for combination therapy in solid cancers, Cancer Res 67 (2007), 2187-2196.

[28] C.M. Ferrell, S.T. Dorsam, H. Ohta, R.K. Humphries, M.K. Derynck, C. Haqq, C. Largman and H.J. Lawrence, Activation of stem-cell specific genes by HOXA9 and HOXA10 homeodomain proteins in CD34+ human cord blood cells, Stem Cells 23 (2005), 644-655.

[29] I. Fishel, A. Kaufman and E. Ruppin, Meta-Analysis of Gene Expression Data: A Predictor-Based Approach, Bioinformatics (2007).

[30] E. Gabrielson, Worldwide trends in lung cancer pathology, Respirology 11 (2006), 533-538.

[31] R.W. Georgantas, III, R. Hildreth, S. Morisot, J. Alder, C.G. Liu, S. Heimfeld, G.A. Calin, C.M. Croce and C.I. Civin, $\mathrm{CD}^{+}{ }^{+}$hematopoietic stem- progenitor cell microRNA expression and function: a circuit diagram of differentiation control, Proc Natl Acad Sci USA 104 (2007), 2750-2755.

[32] A. Giangreco, S.D. Reynolds and B.R. Stripp, Terminal bronchioles harbor a unique airway stem cell population that localizes to the bronchoalveolar duct junction, Am J Pathol 161 (2002), 173-182.

[33] K.L. Grinnell, B. Yang, R.L. Eckert and J.R. Bickenbach, De-differentiation of mouse interfollicular keratinocytes by the embryonic transcription factor Oct-4, J Invest Dermatol 127 (2007), 372-380.

[34] D.J. Gross, G. Munter, M. Bitan, T. Siegal, A. Gabizon, R. Weitzen, O. Merimsky, A. Ackerstein, A. Salmon, A. Sella and S. Slavin, The role of imatinib mesylate (Glivec) for treatment of patients with malignant endocrine tumors positive for c-kit or PDGF-R, Endocr Relat Cancer 13 (2006), 535-540.

[35] M. Gutova, J. Najbauer, A. Gevorgyan, M.Z. Metz, Y. Weng, C.C. Shih and K.S. Aboody, Identification of uPAR-positive Chemoresistant Cells in Small Cell Lung Cancer, PLoS ONE 2 (2007), e243.

[36] E.M. Hansson, U. Lendahl and G. Chapman, Notch signaling in development and disease, Semin Cancer Biol 14 (2004), 320-328.

[37] D.H. Harpole and S.L. Meyerson, Lung cancer staging: proteomics, Thorac Surg Clin 16 (2006), 339-343.

[38] S. Hatfield and H. Ruohola-Baker, microRNA and stem cell function, Cell Tissue Res 331 (2008), 57-66.

[39] B. He, R.N. Barg, L. You, Z. Xu, N. Reguart, I. Mikami, S. Batra, R. Rosell and D.M. Jablons, Wnt signaling in stem cells and non-small-cell lung cancer, Clin Lung Cancer 7 (2005), 54-60.

[40] K. Hibi, T. Takahashi, Y. Sekido, R. Ueda, T. Hida, Y. Ariyoshi, H. Takagi and T. Takahashi, Coexpression of the stem cell factor and the c-kit genes in small-cell lung cancer, Oncogene 6(12) (Dec 1991), 2291-2296.

[41] C. Hirschmann-Jax, A.E. Foster, G.G. Wulf, J.G. Nuchtern, T.W. Jax, U. Gobel, M.A. Goodell and M.K. Brenner, A distinct "side population" of cells with high drug efflux capacity in human tumor cells, Proc Natl Acad Sci USA 101 (2004), $14228-14233$.

[42] M.M. Ho, A.V. Ng, S. Lam and J.Y. Hung, Side population in human lung cancer cell lines and tumors is enriched with stem-like cancer cells, Cancer Res 67 (2007), 4827-4833.

[43] K.U. Hong, S.D. Reynolds, S. Watkins, E. Fuchs and B.R. Stripp, Basal cells are a multipotent progenitor capable of renewing the bronchial epithelium, Am J Pathol 164 (2004), 577-588.

[44] T. Ito, N. Udaka, T. Yazawa, K. Okudela, H. Hayashi, T. Sudo, F. Guillemot, R. Kageyama and H. Kitamura, Basic helix-loop-helix transcription factors regulate the neuroendocrine differentiation of fetal mouse pulmonary epithelium, Development 127 (2000), 3913-3921.

[45] A. Jemal, R. Siegel, E. Ward, T. Murray, J. Xu and M.J. Thun, Cancer statistics, 2007, CA Cancer J Clin 57 (2007), 43-66.

[46] T.A. Juopperi, W. Schuler, X. Yuan, M.I. Collector, C.V. Dang and S.J. Sharkis, Isolation of bone marrow-derived stem cells using density-gradient separation, Exp Hematol 35 (2007), 335-341.

[47] Y. Kang, M. Omura, A. Suzuki, T. Oka, Y. Nakagami, C. Cheng, Y. Nagashima and T. Inoue, Development of an orthotopic transplantation model in nude mice that simulates the clinical features of human lung cancer, Cancer Sci 97 (2006), 996-1001.

[48] H. Kato, Y. Ichinose, M. Ohta, E. Hata, N. Tsubota, H. Tada, Y. Watanabe, H. Wada, M. Tsuboi, N. Hamajima and M. Ohta, A randomized trial of adjuvant chemotherapy with uracil-tegafur for adenocarcinoma of the lung, $N$ Engl J Med 350 (2004), 1713-1721.

[49] C.F. Kim, E.L. Jackson, A.E. Woolfenden, S. Lawrence, I. Babar, S. Vogel, D. Crowley, R.T. Bronson and T. Jacks, Identification of bronchioalveolar stem cells in normal lung and lung cancer, Cell 121 (2005), 823-835.

[50] J. Kim, L. You, Z. Xu, K. Kuchenbecker, D. Raz, B. He and D. Jablons, Wnt inhibitory factor inhibits lung cancer cell growth, J Thorac Cardiovasc Surg 133 (2007), 733-737.

[51] N. Kim and T.H. Vu, Parabronchial smooth muscle cells and alveolar myofibroblasts in lung development, Birth Defects Res C Embryo Today 78 (2006), 80-89. 
[52] T. Kondo, T. Setoguchi and T. Taga, Persistence of a small subpopulation of cancer stem-like cells in the C6 glioma cell line, Proc Natl Acad Sci USA 101 (2004), 781-786.

[53] M. Lako, T. Strachan, P. Bullen, D.I. Wilson, S.C. Robson and S. Lindsay, Isolation, characterisation and embryonic expression of WNT11, a gene which maps to $11 \mathrm{q} 13.5$ and has possible roles in the development of skeleton, kidney and lung, Gene 219 (1998), 101-110.

[54] W.K. Lam, Lung cancer in Asian women-the environment and genes, Respirology 10 (2005), 408-417.

[55] Q.T. Le, E. Chen, A. Salim, H. Cao, C.S. Kong, R. Whyte, J. Donington, W. Cannon, H. Wakelee, R. Tibshirani, J.D. Mitchell, D. Richardson, K.J. O’Byrne, A.C. Koong and A.J. Giaccia, An evaluation of tumor oxygenation and gene expression in patients with early stage non-small cell lung cancers, Clin Cancer Res 12 (2006), 1507-1514.

[56] L.N. Lee, S.H. Kuo, Y.C. Lee, Y.L. Chang, H.C. Chang, I.S. Jan and P.C. Yang, CD44 splicing pattern is associated with disease progression in pulmonary adenocarcinoma, $J$ Formos Med Assoc 104 (2005), 541-548.

[57] C. Leimeister, A. Externbrink, B. Klamt and M. Gessler, Hey genes: a novel subfamily of hairy- and Enhancer of split related genes specifically expressed during mouse embryogenesis, Mech Dev 85 (1999), 173-177.

[58] C. Li, J. Xiao, K. Hormi, Z. Borok and P. Minoo, Wnt5a participates in distal lung morphogenesis, Dev Biol 248 (2002), 68-81.

[59] E. Lim, Y.K. Yap, B.L. De Stavola, A.G. Nicholson and P. Goldstraw, The impact of stage and cell type on the prognosis of pulmonary neuroendocrine tumors, $J$ Thorac Cardiovasc Surg 130 (2005), 969-972.

[60] Y. Litingtung, L. Lei, H. Westphal and C. Chiang, Sonic hedgehog is essential to foregut development, Nat Genet $\mathbf{2 0}$ (1998), 58-61.

[61] J. Liu and G. Jiang, CD44 and hematologic malignancies, Cell Mol Immunol 3 (2006), 359-365.

[62] W.J. Mackillop, A. Ciampi, J.E. Till and R.N. Buick, A stem cell model of human tumor growth: implications for tumor cell clonogenic assays, J Natl Cancer Inst 70 (1983), 9-16.

[63] S.M. Majka, M.A. Beutz, M. Hagen, A.A. Izzo, N. Voelkel and K.M. Helm, Identification of novel resident pulmonary stem cells: form and function of the lung side population, Stem Cells 23 (2005), 1073-1081.

[64] J.D. Minna, J.A. Roth and A.F. Gazdar, Focus on lung cancer, Cancer Cell 1 (2002), 49-52.

[65] N. Mitsutake, A. Iwao, K. Nagai, H. Namba, A. Ohtsuru, V. Saenko and S. Yamashita, Characterization of side population in thyroid cancer cell lines: cancer stem-like cells are enriched partly but not exclusively, Endocrinology 148 (2007), 1797-1803.

[66] D. Naor, S. Nedvetzki, I. Golan, L. Melnik and Y. Faitelson, CD44 in cancer, Crit Rev Clin Lab Sci 39 (2002), 527-579.

[67] T.G. Natarajan and K.T. FitzGerald, Markers in normal and cances stem cells, Cancer Biomarkers 3 (2007), 211-231.

[68] J. Neuzil, M. Stantic, R. Zobalova, J. Chladova, X. Wang, L. Prochazka, L. Dong, L. Andera and S.J. Ralph, Tumourinitiating cells vs. cancer 'stem' cells and CD133: what's in the name? Biochem Biophys Res Commun 355 (2007), 855-859.

[69] R. Pardal, M.F. Clarke and S.J. Morrison, Applying the principles of stem-cell biology to cancer, Nat Rev Cancer 3 (2003), 895-902.
[70] D.M. Parkin, P. Pisani and J. Ferlay, Estimates of the worldwide incidence of 25 major cancers in 1990, Int J Cancer $\mathbf{8 0}$ (1999), 827-841.

[71] D.J. Pearce, D. Taussig, C. Simpson, K. Allen, A.Z. Rohatiner, T.A. Lister and D. Bonnet, Characterization of cells with a high aldehyde dehydrogenase activity from cord blood and acute myeloid leukemia samples, Stem Cells 23 (2005), 752-760.

[72] G. Pelosi, M. Barisella, F. Pasini, M.E. Leon, G. Veronesi, L. Spaggiari, F. Fraggetta, A. Iannucci, M. Masullo, A. Sonzogni, F. Maffini and G. Viale, CD117 immunoreactivity in stage I adenocarcinoma and squamous cell carcinoma of the lung: relevance to prognosis in a subset of adenocarcinoma patients, Mod Pathol 17 (2004), 711-721.

[73] M. Pesce and H.R. Scholer, Oct-4: gatekeeper in the beginnings of mammalian development, Stem Cells 19 (2001), 271-278.

[74] E. Pisick, S. Jagadeesh and R. Salgia, Small cell lung cancer: from molecular biology to novel therapeutics, $J$ Exp Ther Oncol 3 (2003), 305-318.

[75] J.E. Pongracz and R.A. Stockley, Wnt signalling in lung development and diseases, Respir Res 7 (2006), 15.

[76] L.C. Post, M. Ternet and B.L. Hogan, Notch/Delta expression in the developing mouse lung, Mech Dev 98 (2000), 95-98.

[77] A. Potti, S. Mukherjee, R. Peterson, H.K. Dressman, A. Bild, J. Koontz, R. Kratzke, M.A. Watson, M. Kelley, G.S. Ginsburg, M. West, D.H. Harpole, Jr. and J.R. Nevins, A genomic strategy to refine prognosis in early-stage non-small-cell lung cancer, The New England Journal of Medicine 355 (2006), 570-580.

[78] T. Reya, S.J. Morrison, M.F. Clarke and I.L. Weissman, Stem cells, cancer, and cancer stem cells, Nature 414 (2001), 105111.

[79] S.D. Reynolds, A. Giangreco, J.H. Power and B.R. Stripp, Neuroepithelial bodies of pulmonary airways serve as a reservoir of progenitor cells capable of epithelial regeneration, $\mathrm{Am}$ J Pathol 156 (2000), 269-278.

[80] S.D. Reynolds, H. Shen, P.R. Reynolds, T. Betsuyaku, J.M. Pilewski, F. Gambelli, M. Deguiseppe, L.A. Ortiz and B.R. Stripp, Molecular and functional properties of lung SP cells, Am J Physiol Lung Cell Mol Physiol 292 (2007), L972-L983.

[81] J. Russo, A. Barnes, K. Berger, J. Desgrosellier, J. Henderson, A. Kanters and L. Merkov, 4-(N,Ndipropylamino)benzaldehyde inhibits the oxidation of alltrans retinal to all-trans retinoic acid by ALDH1A1, but not the differentiation of HL-60 promyelocytic leukemia cells exposed to all-trans retinal, BMC Pharmacol 2 (2002), 4.

[82] G.V. Scagliotti, F. Michelotto, G. Kalikatzaros, E. Leonardo, S. Cappia, L. Gubetta, P. Borasio and E. Pozzi, Detection of multidrug resistance associated P-170 glycoprotein in previously untreated non small cell lung cancer, Anticancer Res 11 (1991), 2207-2210.

[83] J.B. Schnier, G. Kaur, A. Kaiser, S.F. Stinson, E.A. Sausville, J. Gardner, K. Nishi, E.M. Bradbury and A.M. Senderowicz, Identification of cytosolic aldehyde dehydrogenase 1 from non-small cell lung carcinomas as a flavopiridol-binding protein, FEBS Lett 454 (1999), 100-104.

[84] L.V. Sequist, D.W. Bell, T.J. Lynch and D.A. Haber, Molecular predictors of response to epidermal growth factor receptor antagonists in non-small-cell lung cancer, $J$ Clin Oncol $\mathbf{2 5}$ (2007), 587-595.

[85] S.V. Shmelkov, R. St Clair, D. Lyden and S. Rafii, AC133/CD133/Prominin-1, Int J Biochem Cell Biol 37 (2005), 715-719. 
[86] W. Shu, Y.Q. Jiang, M.M. Lu and E.E. Morrisey, Wnt7b regulates mesenchymal proliferation and vascular development in the lung, Development 129 (2002), 4831-4842.

[87] G.H. Smith, Label-retaining epithelial cells in mouse mammary gland divide asymmetrically and retain their template DNA strands, Development 132 (2005), 681-687.

[88] V. Sriuranpong, M.W. Borges, R.K. Ravi, D.R. Arnold, B.D. Nelkin, S.B. Baylin and D.W. Ball, Notch signaling induces cell cycle arrest in small cell lung cancer cells, Cancer Res 61 (2001), 3200-3205.

[89] V. Sriuranpong, M.W. Borges, C.L. Strock, E.K. Nakakura, D.N. Watkins, C.M. Blaumueller, B.D. Nelkin and D.W. Ball, Notch signaling induces rapid degradation of achaete-scute homolog 1, Mol Cell Biol 22 (2002), 3129-3139.

[90] C. Steidl, C. Leimeister, B. Klamt, M. Maier, I. Nanda, M. Dixon, R. Clarke, M. Schmid and M. Gessler, Characterization of the human and mouse HEY1, HEY2, and HEYL genes: cloning, mapping, and mutation screening of a new bHLH gene family, Genomics 66 (2000), 195-203.

[91] R. Summer, D.N. Kotton, X. Sun, B. Ma, K. Fitzsimmons and A. Fine, Side population cells and Bcrp1 expression in lung, Am J Physiol Lung Cell Mol Physiol 285 (2003), L97-104.

[92] K. Uematsu, B. He, L. You, Z. Xu, F. McCormick and D.M. Jablons, Activation of the Wnt pathway in non small cell lung cancer: evidence of dishevelled overexpression, Oncogene 22 (2003), 7218-7221.

[93] D.M. van der, E.G. de Vries, W. Timens, R.J. Scheper, H. Timmer-Bosscha and D.S. Postma, ATP-binding cassette (ABC) transporters in normal and pathological lung, Respir Res 6 (2005), 59.

[94] A.L. Vescovi, R. Galli and B.A. Reynolds, Brain tumour stem cells, Nat Rev Cancer 6 (2006), 425-436.

[95] J. Vestergaard, M.W. Pedersen, N. Pedersen, C. Ensinger, Z. Tumer, N. Tommerup, H.S. Poulsen and L.A. Larsen, Hedgehog signaling in small-cell lung cancer: frequent in vivo but a rare event in vitro, Lung Cancer 52 (2006), 281290.

[96] Z. Wang, W. Shu, M.M. Lu and E.E. Morrisey, Wnt7b activates canonical signaling in epithelial and vascular smooth muscle cells through interactions with Fzd1, Fzd10, and LRP5, Mol Cell Biol 25 (2005), 5022-5030.

[97] D. Warburton, S. Bellusci, S. De Langhe, P.M. Del Moral, V. Fleury, A. Mailleux, D. Tefft, M. Unbekandt, K. Wang and W.
Shi, Molecular mechanisms of early lung specification and branching morphogenesis, Pediatr Res 57 (2005), 26R-37R.

[98] D. Warburton, C. Wuenschell, G. Flores-Delgado and K. Anderson, Commitment and differentiation of lung cell lineages, Biochem Cell Biol 76 (1998), 971-995.

[99] D.N. Watkins, D.M. Berman, S.G. Burkholder, B. Wang, P.A. Beachy and S.B. Baylin, Hedgehog signalling within airway epithelial progenitors and in small-cell lung cancer, Nature 422 (2003), 313-317.

[100] I.L. Weissman, D.J. Anderson and F. Gage, Stem and progenitor cells: origins, phenotypes, lineage commitments, and transdifferentiations, Annu Rev Cell Dev Biol 17 (2001), 387-403.

[101] T. Winton, R. Livingston, D. Johnson, J. Rigas, M. Johnston, C. Butts, Y. Cormier, G. Goss, R. Inculet, E. Vallieres, W. Fry, D. Bethune, J. Ayoub, K. Ding, L. Seymour, B. Graham, M.S. Tsao, D. Gandara, K. Kesler, T. Demmy and F. Shepherd, Vinorelbine plus cisplatin vs. observation in resected nonsmall-cell lung cancer, $N$ Engl J Med 352 (2005), 2589-2597.

[102] E.L. Wynder and J.E. Muscat, The changing epidemiology of smoking and lung cancer histology, Environ Health Perspect 103(Suppl 8) (1995), 143-148.

[103] S. Yanagi, H. Kishimoto, K. Kawahara, T. Sasaki, M. Sasaki, M. Nishio, N. Yajima, K. Hamada, Y. Horie, H. Kubo, J.A. Whitsett, T.W. Mak, T. Nakano, M. Nakazato and A. Suzuki, Pten controls lung morphogenesis, bronchioalveolar stem cells, and onset of lung adenocarcinomas in mice, $J$ Clin Invest 117 (2007), 2929-2940.

[104] N. Yanaihara, N. Caplen, E. Bowman, M. Seike, K. Kumamoto, M. Yi, R.M. Stephens, A. Okamoto, J. Yokota, T. Tanaka, G.A. Calin, C.G. Liu, C.M. Croce and C.C. Harris, Unique microRNA molecular profiles in lung cancer diagnosis and prognosis, Cancer Cell 9 (2006), 189-198.

[105] L. You, B. He, Z. Xu, K. Uematsu, J. Mazieres, I. Mikami, N. Reguart, T.W. Moody, J. Kitajewski, F. McCormick and D.M. Jablons, Inhibition of Wnt-2-mediated signaling induces programmed cell death in non-small-cell lung cancer cells, Oncogene 23 (2004), 6170-6174.

[106] S. Zhou, J.J. Morris, Y. Barnes, L. Lan, J.D. Schuetz and B.P. Sorrentino, Bcrp1 gene expression is required for normal numbers of side population stem cells in mice, and confers relative protection to mitoxantrone in hematopoietic cells in vivo, Proc Natl Acad Sci USA 99 (2002), 12339-12344. 


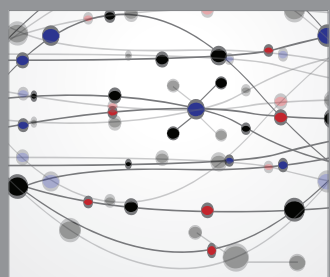

The Scientific World Journal
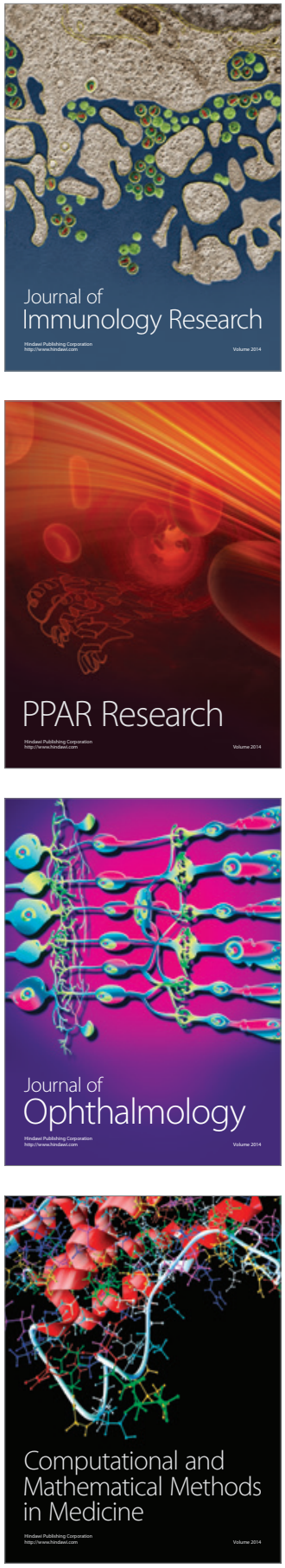

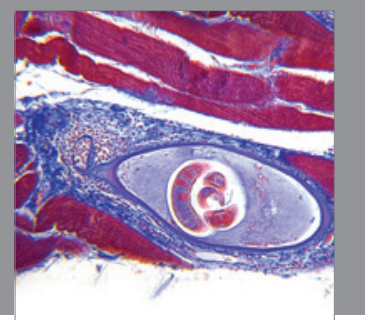

Gastroenterology

Research and Practice
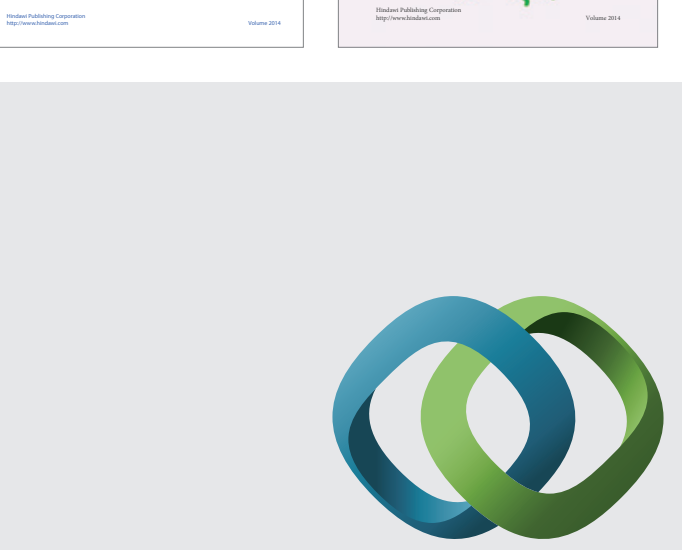

\section{Hindawi}

Submit your manuscripts at

http://www.hindawi.com
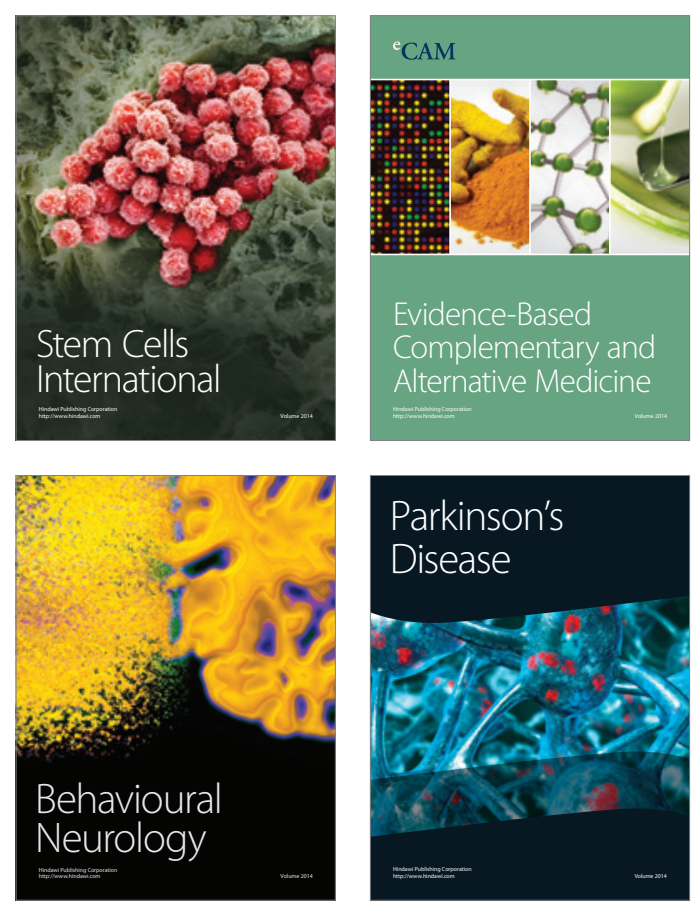

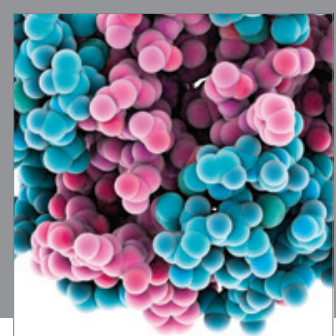

Journal of
Diabetes Research

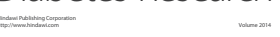

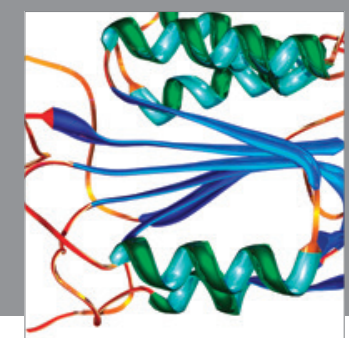

Disease Markers
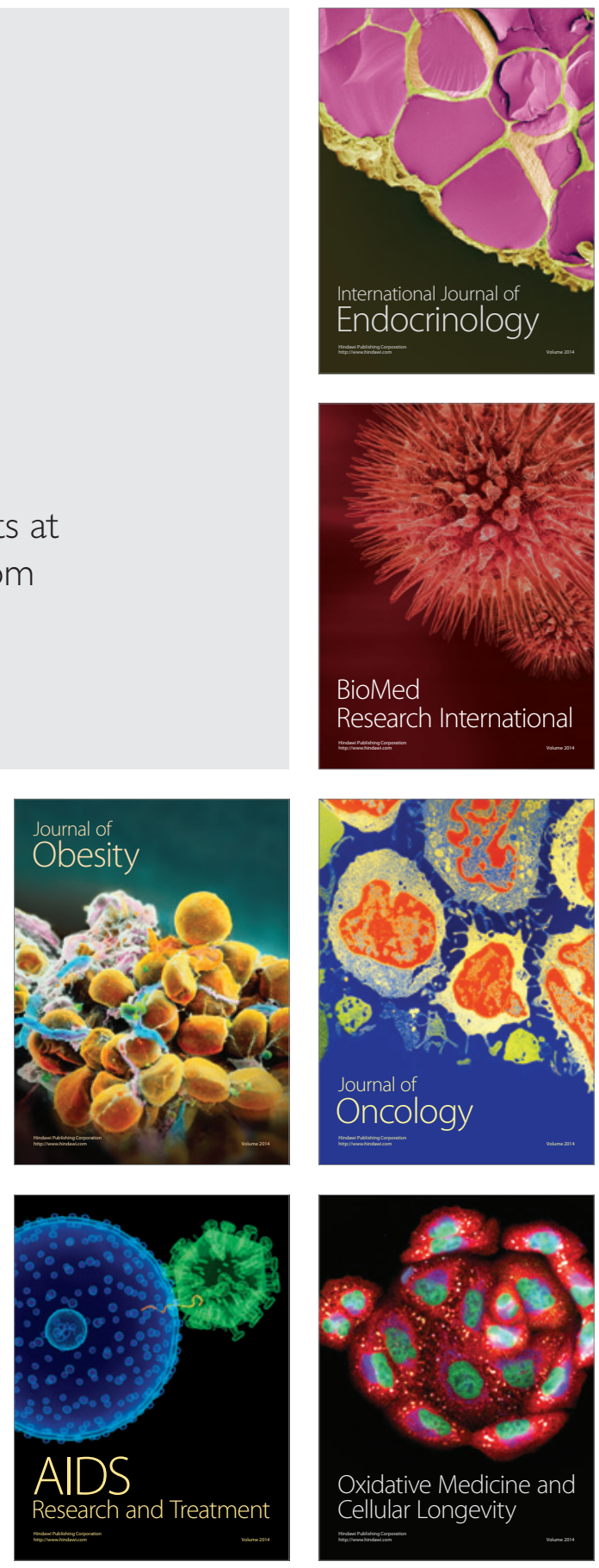